\title{
Erratum to: Dynamic probabilistic design approach of high-pressure turbine blade-tip radial running clearance
}

\author{
Cheng-Wei Fei • Yat-Sze Choy • Dian-Yin Hu • \\ Guang-Chen Bai · Wen-Zhong Tang
}

Published online: 8 August 2016

(C) Springer Science+Business Media Dordrecht 2016

\section{Erratum to: Nonlinear Dyn DOI 10.1007/s11071-016-2883-1}

In the original publication, references [9] and [11] were incorrectly specified as duplicates of [3] and [7], resp. For the correct references [9] and [11], see below list.

Furthermore, the following lines in the second paragraph of the Introduction should be re-phrased:

"Hennecke et al. [9] developed the turbine tip clearance control in gas turbine engines;" should be changed into "Khorrami et al. [9] developed a novel approach for reducing rotor tip-clearance;"
"Pillidis et al. [11] built the prediction models of tip clearance changes in gas turbines;" should be changed into "Peng et al. [11] gave an active generalized predictive control strategy of turbine tip clearance for aeroengines;"

\section{References}

9. Khorrami, M.R., Li, F.: A novel approach for reducing rotor tip-clearance induced noise in turbofan engines. In: 7th AIAA/CEAS Aeroacoustics Conference, 28-30 May, 2001, Maastricht, Netherlands, AIAA-2001-2148

11. Peng, K., Fan, D., Yang, F., et al.: Active generalized predictive control of turbine tip clearance for aero-engines. Chin. J. Aeronaut. 26, 1147-1155 (2013)

The online version of the original article can be found under doi:10.1007/s11071-016-2883-1.

C.-W. Fei $(\varangle) \cdot$ Y.-S. Choy

Department of Mechanical Engineering, The Hong Kong Polytechnic University, Hung Hom, Kowloon, Hong Kong, People's Republic of China e-mail: feicw544@163.com

C.-W. Fei · D.-Y. Hu • G.-C. Bai

School of Energy and Power Engineering,

Beijing University of Aeronautics and Astronautics,

Beijing 100191, People's Republic of China

W.-Z. Tang

School of Computer Science and Engineering,

Beijing University of Aeronautics and Astronautics,

Beijing 100191, People's Republic of China 